\title{
PEQUENA OBRA MAESTRA DE LA ESCULTURA OLMECA
}

\author{
Por Beatriz de la Fuente
}

E1 Museo de Antropología de la Universidad Veracruzana en Xalapa, cuenta, entre sus tesoros artísticos y arqueológicos, con una pequeña escultura que, a pesar de ser excepcional, no ha suscitado interés entre los estudiosos del arte y de la cultura olmeca.

Se trata de una figura humana con escasos $12.3 \mathrm{~cm}$ de altura, $4.3 \mathrm{~cm}$ de ancho, $2 \mathrm{~cm}$ de espesor y 188 gxamos de peso. Tallada en jadeíta, procede, junto con muchos otros objetos de tamaño reducido -hachas, máscaras, figurillas-, de una ofrenda encontrada de manera casual en el lecho no muy profundo del río de Las Choapas en Veracruz. Algunos de esos abjetos, me refiero en particular a las máscaras, son piezas úni. cas que destacan entre otros cientos de imágenes olmecas por su peculiar calidad artística, el cuidado de la talla en la fina piedra y el pulimento perfecto del acabado. Las piedras en que tales objetos fueron fabricados son conocidas como serpentinas, de grano fino, muy cerrado y de diver sos colores; las hay desde en tonos claros, marfilinos, hasta en otros más oscuros: grises, cafés y verdes, con predominio de estos últimos; en su mayoría son piedras duras, semejantes al mármol en su consistencia. Por la abundancia de objetos en este material, y por su parecido con la jadeíta, puede tenerse como probable que durante los tiempos prehispánicos haya tenido un simbolismo especial.

La figurilla humana de que hoy me ocupo, no escapa a las cualidades propias de los otros objetos procedentes del tío de Las Choapas; virtuosismo y maestría en la talla y en el acabado, y tiene al igual que las otras un sello distintivo, el del estilo local, que la distancia del conjunto de esculturas olmecas de tamaño menor.

Esculpida como un objeto de tres dimensiones, la figurilla muestra distintos y consecuentes acercamientos (figura 1). Pequeño bloque de compacta estructura, pesado en apariencia, xígido en su postura y severamente enérgico en expresión. Sus formas responden al estilo total al que se integra: volúmenes geometrizantes - cuerpo y extremidades son un prisma rectangular, en tanto que la cabeza es un cubo-, superficies redondeadas en lugar de axistas, síntesis esquemáticas de los rasgos corporales "El rostro, como es usual, es lo único tallado con minuciosa acuciosidad.

Exhibe, al igual que otras esculturas hermanas suyas, solida gravita- 
ción; los pies son la plataforma de donde arrancan, cual pilares que sostienen el cuerpo, las piernas cortas e inmóviles; el cuerpo mismo está cubierto en su mitad inferior por una falda ajustada en la cintura por medio de un ceñidor y el torso que por encima se desprende, desnudo, revela en los cortes definidos de sus rasgos la constitución propia del hombre olmeca: hombros echados hacia el frente, vientre abultado, tetillas adiposas y brazos de recia musculatura. Las manos se han figurado en pormenor y todo, cuerpo y extremidades, se ha reducido a esenciales estructuras geométricas.

No ocurre lo mismo con el rostro, o más bien con la cabeza entera, la cual se mira encajada, sin cuello, en el centro de la línea curva que se forma de la unión de los hombros (figura 2). La cabeza, cubo de esquinas redondeadas, está cubierta por una especie de tocado que la envuelve en su totalidad, y deja tan sólo asomar la cara. En ésta se ve, dentro del corte agudo de la talla, discreta individualidad. Los grandes ojos son elípticos, con los párpados realzados por un reborde y las pupilas en relieve. Son ojos muy abiertos que miran fija y penetrantemente. El entrecejo fruncido está dividido en dos carnosidades, es abultado porque el casquete está ceñido a presión sobre la cabeza. La nariz, amplia y chata, luce como puente triangular, con el vértice en el entrecejo y con la base paralela al borde del labio superior. El conjunto del rostro es ligeramente prognata, con labios cerrados, rectos y planos, y mejillas robustas que se articulan en el sobresaliente mentón.

El tocado sugiere, debido al modo como se adapta a la cabeza, la imitación de un material flexible, acaso cuero o algodón; está constituido por dos secciones, la inferior o banda que cubre la frente y se continúa por los lados, hasta las mejillas, y el casquete que culmina en la parte media central y posterior, con una proyección vertical. La banda tiene como único elemento que quiebra, la superficie lisa, una forma semicircular resaltada; recuerda la que se aprecia en el mismo lugar de la Cabeza Colosal, Monumento 1, de San Lorenzo (figura 3). Al igual que en las cabezas colosales, una acanaladura separa la banda del casquete, pero a diferencia de ellas, que muestran siempre las orejas estilizadas pero conforme al modo natural, esta pequeña figura humana lleva dos resaltes rectangulares que las sustituyen o las cubren por completo. Tengo para mí que esta escultura de tamaño reducido es ciertamente original y única en su género. Su carácter humano y sus rasgos individuales no tienen paralelo entre los objetos de pequeño formato. Es, acaso, equipara- 
DOI: http://dx.doi.org/10.22201/iie.18703062e.1977.47.1084

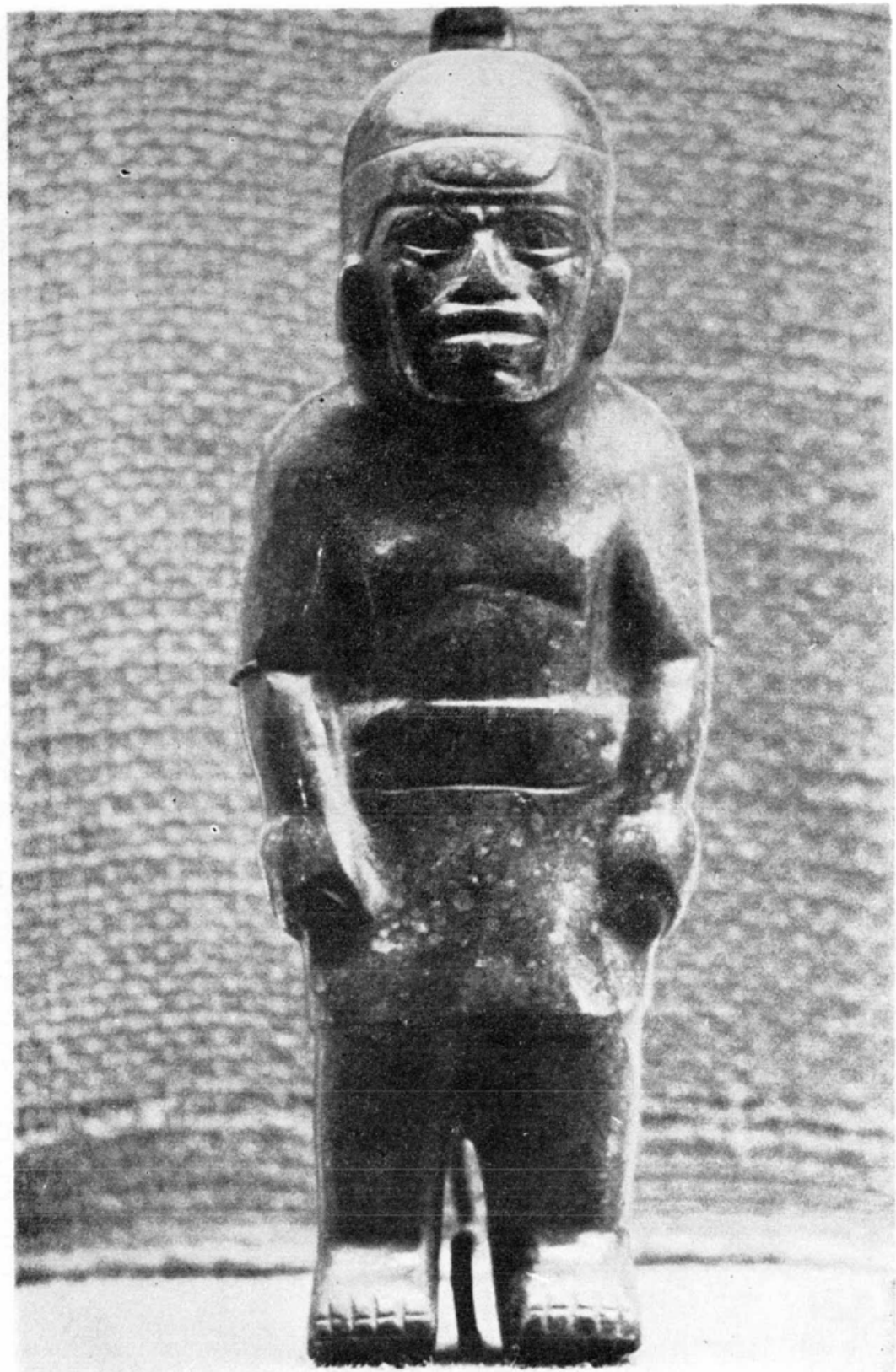

Figura 1. Figurilla de Las Choapas. Museo de Antropología, Universidad Veracruzana. Foto de Elisa Vargas Lugo. 


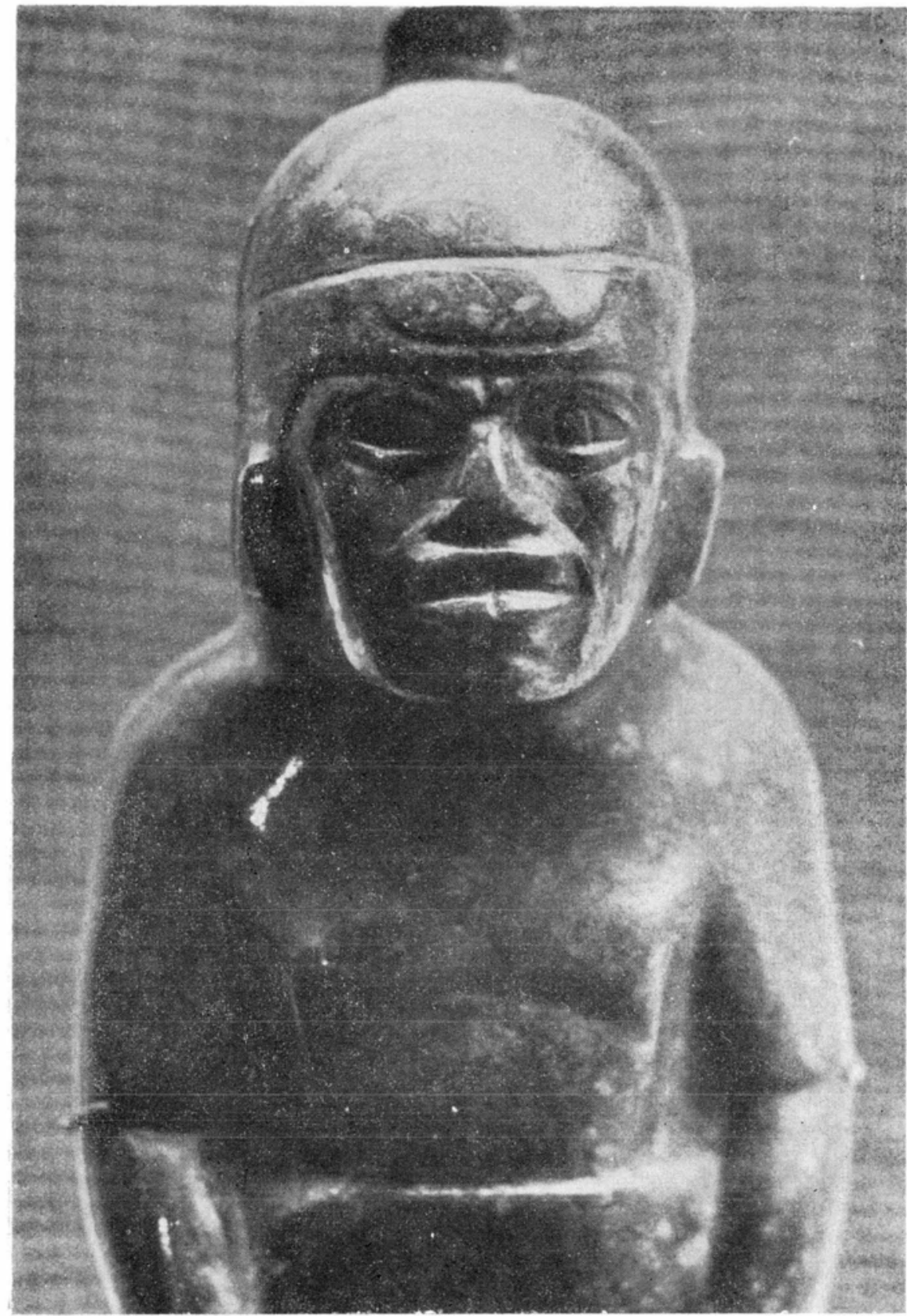

Figura 2. Figurilla de Las Choapas. Detalle. Museo de Antropología, Universidad Veracruzana. Foto de Elisa Vargas Lugo. 
DOI: http://dx.doi.org/10.22201/iie.18703062e.1977.47.1084

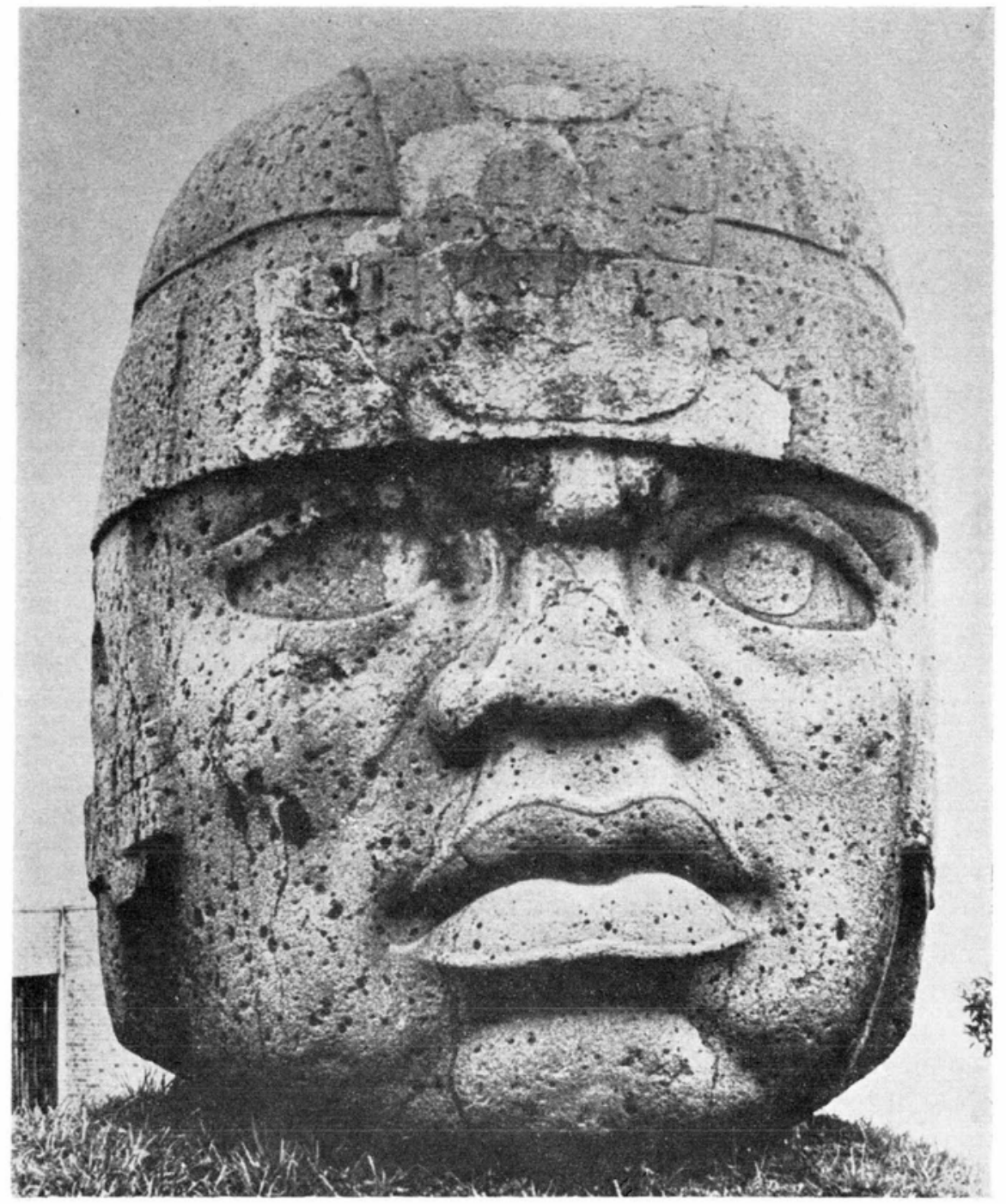

Figura 3. Cabeza Colosal 1 de San Lorenzo. Foto de Beatriz de la Fuente. 

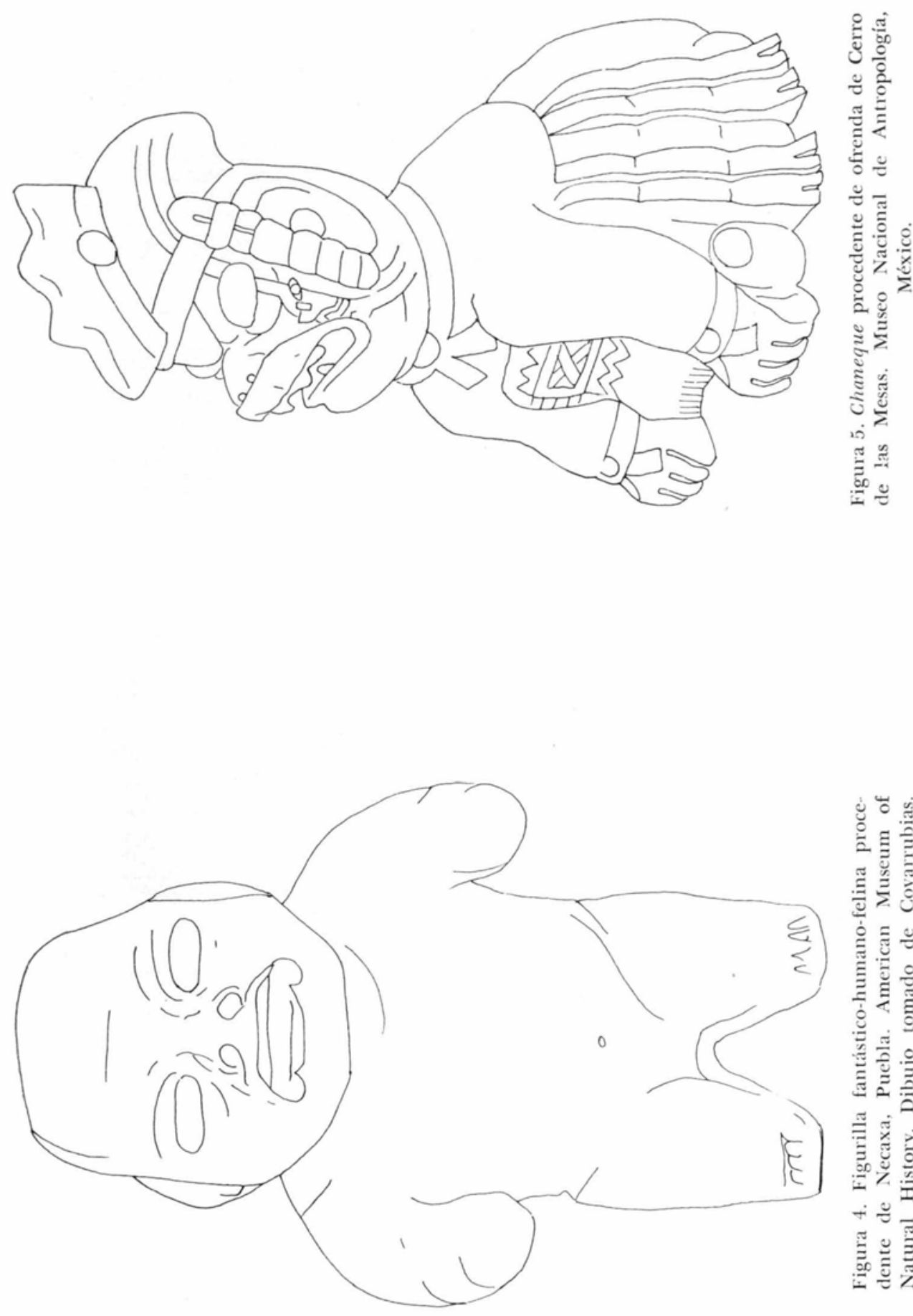

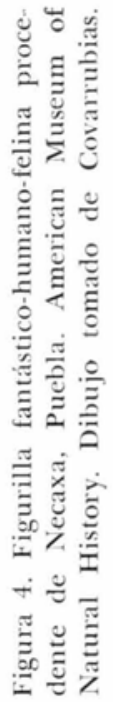


DOI: http://dx.doi.org/10.22201/iie.18703062e.1977.47.1084
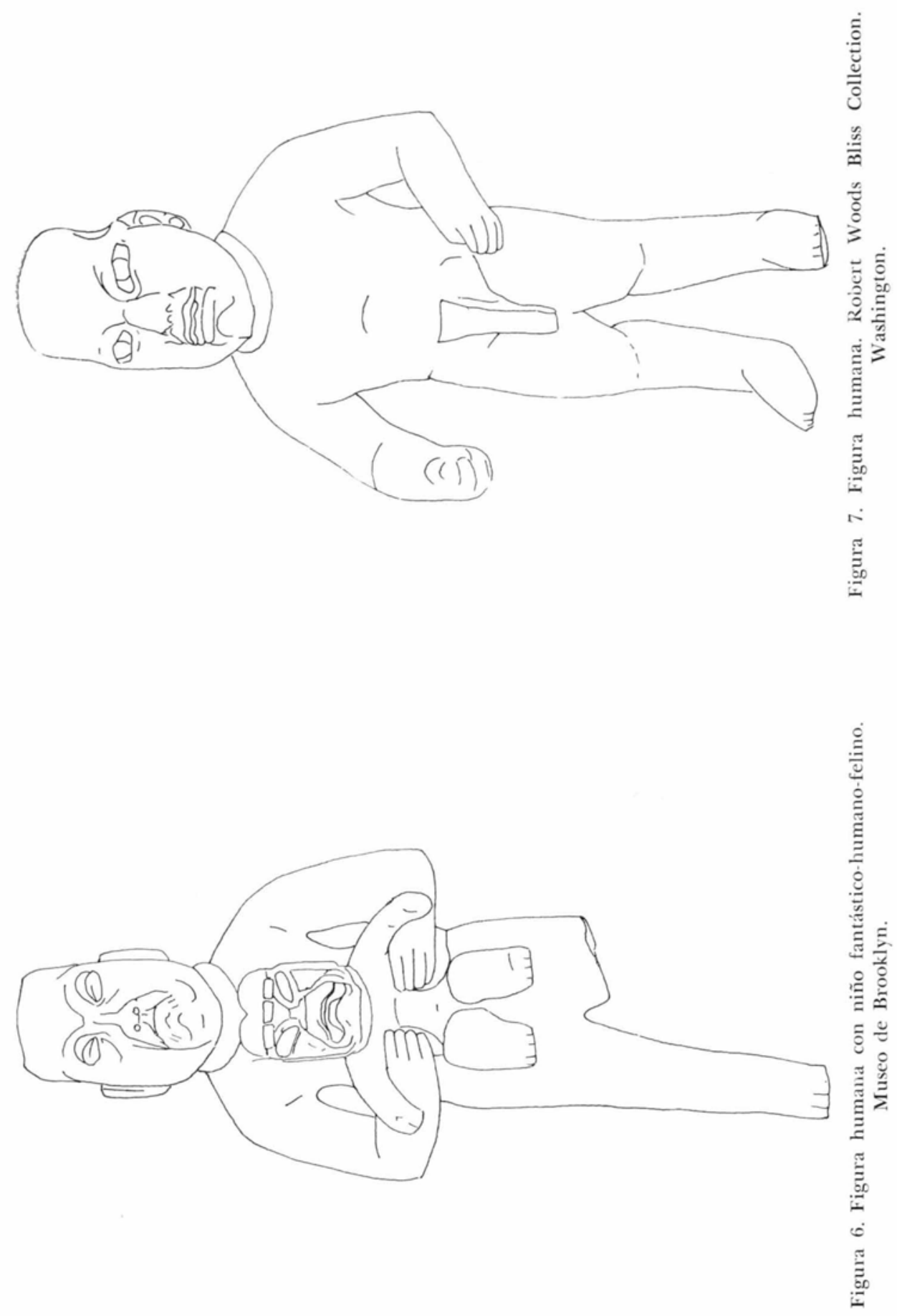
DOI: http://dx.doi.org/10.22201/iie.18703062e.1977.47.1084

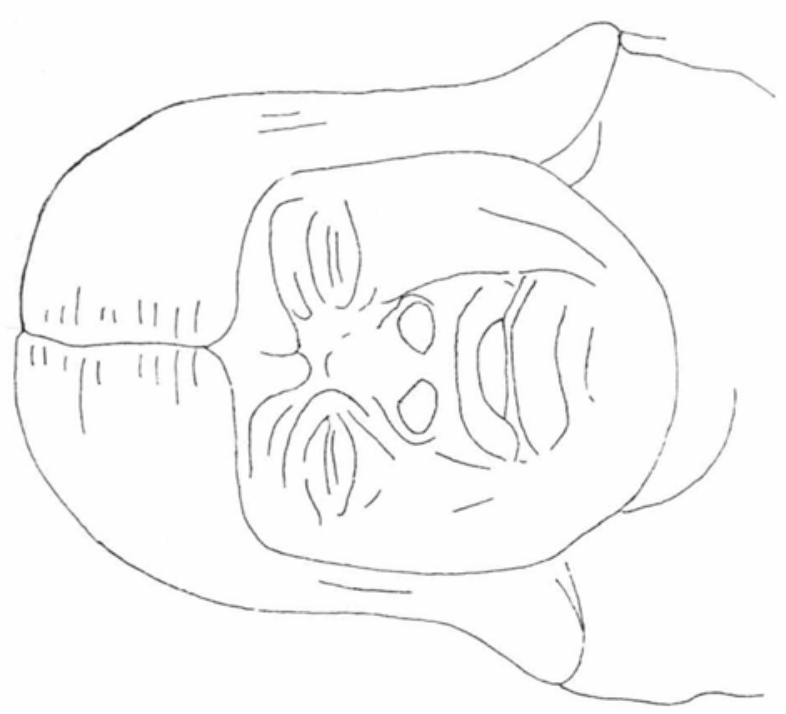

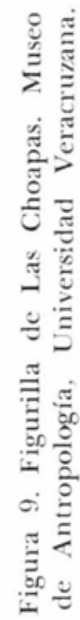

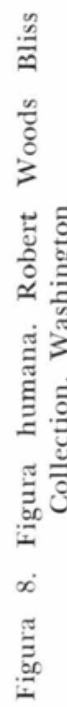


DOI: http://dx.doi.org/10.22201/iie.18703062e.1977.47.1084

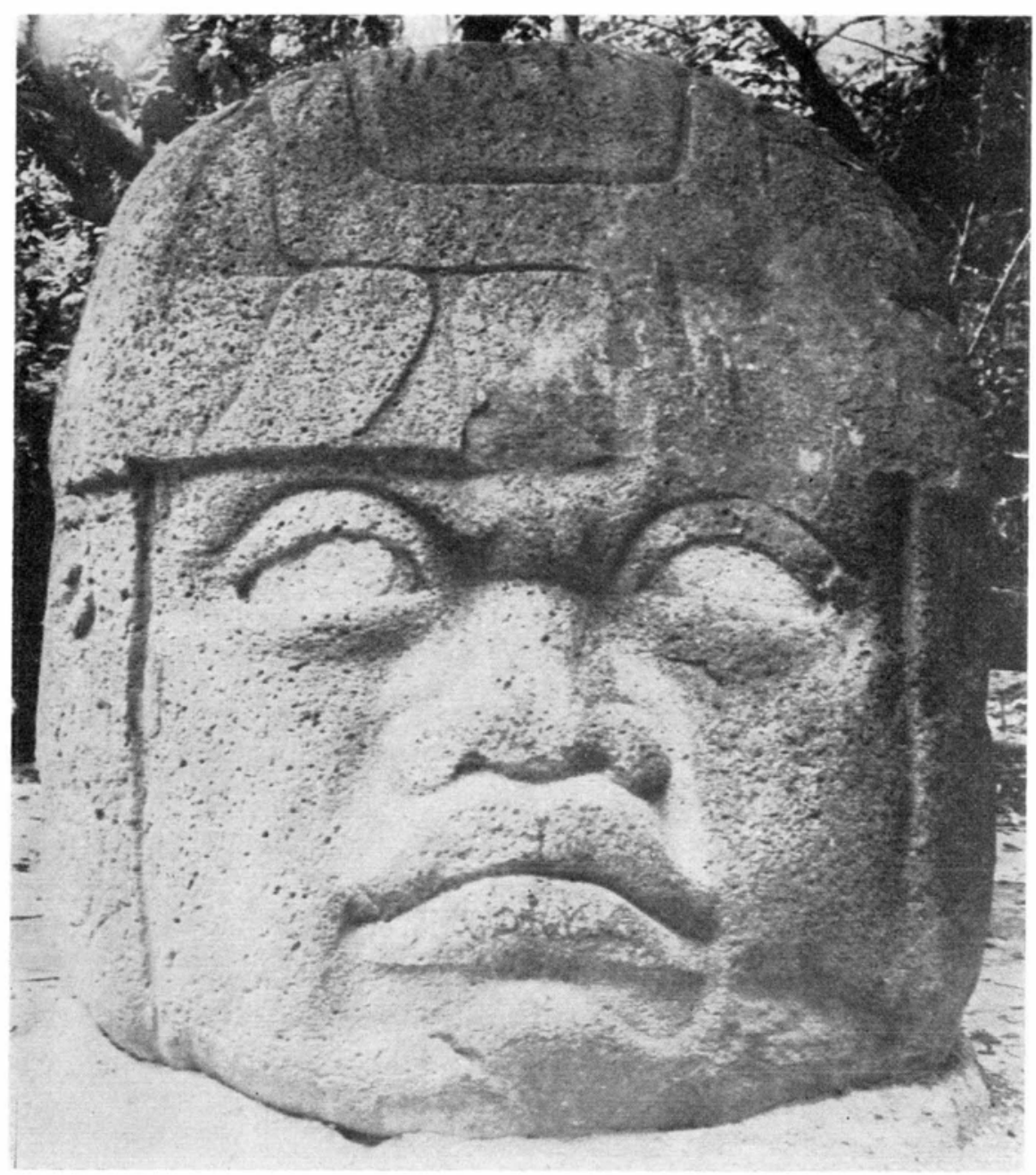

Figura 10. Cabeza Colosal 1 de La Venta. Fcto de Beatriz de la Fuente. 
DOI: http://dx.doi.org/10.22201/iie.18703062e.1977.47.1084 
ble con algunas esculturas monumentales; en concreto, con las cabezas colosales, respecto de las cuales guarda similitudes sorprendentes.

De los pequeños objetos olmecas tallados preferentemente en jade, jadeíta o en otras piedras verdes parecidas, destacan conjuntos tales como las hachas, las celtas, las máscaras, las placas incisas, los punzones, las canoas y las figurillas de aspecto primordialmente humano.

Entre estas últimas se aprecian, cuando menos, tres grandes conjuntos: el primero constituido por las que son menos numerosas, las representaciones fantástico-humano-felinas, imágenes en que a un cuerpo esencialmente humano se añaden rasgos imaginados y otros que se toman del jaguar -como la figurilla de jade procedente de Necaxa, Puebla, hoy en el American Museum of Natural History (figura 4); el segundo corresponde al grupo de los llamados chaneques, figuras de seres deformes, enanos o jorobados - como algunas de la ofrenda de La Venta y de Cerro de las Mesas, en el Museo Nacional de Antropología (figura 5), $y$, finalmente, el de las figurillas característicamente humanas. En este último conjunto se pueden distinguir dos diferentes categorías: una de figuras esbeltas, de extremidades alargadas, cabeza deforme semejante a una pera, cránco rasurado, orejas u orejeras como angostos rectángulos verticales, ojos ovales, nariz chata y boca de gruesos labios, con las comisuras caídas hacia abajo, con frecuencia entreabiertos mostrando las encías desdentadas. Ciertos autores se refieren a estas figuras como baby-face (Pohorilenko, 1972), pues aunque no corresponden del todo a la clásica definición de tal tipo de imágenes (Covarrubias, 1961:63), sus caras, sobre cuerpos de adultos, no dejan de tener aspecto infantil. Son, tal vez, las figurillas más abundantes - como algunas de ofrendas de La Venta en el Museo Nacional de Antropología o en la Robert Woods Bliss Collection de Washington (figura 6). En esta misma categoría deben quedar incluidas, por su apariencia externa, las figuras que sostienen en sus manos una imagen más pequeña del tipo fantástico-humano-felino, como la del Museo de Brooklyn (figura 7). En su totalidad son representaciones carentes de carácter individual, predomina en ellas la convención, se reproduce un modelo general previamente fijado, pretenden simbolizar a un ser sagrado y sobrenatural - por eso la monótona repetición del esquema de los rasgos estilizados, del patrón establecido.

Una categoría diferente, de la cual hay escasos ejemplos, es aquella en que las representaciones humanas se miran más apegadas a la realidad visible. Se ha procurado imprimirles un sello más humano y personal, por lo que se las ve más cercanas a la naturaleza. Los rostros revelan, 
inclusive, fidelidad a un modelo particular, y en alguna la emoción vital se ve alentada por la expresión. La nota peculiar de estas figurillas es su unicidad; no hay en ellas modelo ni repetición, cada una es, en lo que pretende, personal e inconfundible; éste es su carácter primario. Destacan dos ejemplos extraordinarios, la fragmentada figurilla de traslúcido jade verde de la Robert Woods Bliss Collection en Washington (figura 8), y la pequeña figura del Museo de Antropología de Xalapa (figura 9).

Es evidente que las dos categorías antes mencionadas, de figurillas humanas, responden a contenido diferente, significan distinto concepto y tuvieron diversa finalidad. Símbolos dispares cobran cuerpo en imágenes desiguales. En tanto que las figuras de la primera categoría representan a entes divinos, las de la segunda son retratos de seres reales. El fragmento de la figurilla en la Bliss Collection, con apenas $6 \mathrm{~cm}$ de altura, impresiona vivamente por su realismo vigoroso; la figurilla del Museo de Xalapa llama poderosamente la atención por la individualidad de su aplomo monumental.

Este rasgo de la apariencia monumental a pesar de lo reducido del tamaño, es uno de los que, entre otros, la hacen comparable con las grandes esculturas. Es, ya lo he dicho, en el aspecto formal, un bloque compacto, de estructura y rasgos geometrizantes, de apariencia sólidamente arraigada al suelo, de forma cerrada y de cuerpo esquemáticamente configurado. En el rostro se concentra la particular expresión humana. Tales condiciones se reúnen no en las frágiles figurillas de jade, sino en las tallas colosales.

En la actualidad se conoce una sola escultura monumental repre. sentada de pie, el Monumento 19 de Laguna de los Cerros; pero tanto en la factura de ésta como en el tratamiento de otros cuerpos sedentes, por ejemplo, el Monumento 9 de La Venta, me parece encontrar similitud, precisamente en la economía de elementos, con la figurilla del Museo de Xalapa.

La cabeza no guarda, por su parte, parecido con ninguna de las cabezas de las figuras monumentales sedentes, entre las cuales se conservan completas algunas procedentes de La Venta; su carácter de retrato la vincula directamente con las cabezas colosales. Es así como se acerca a las grandes esculturas en un doble aspecto: el de las cualidades formales que sugieren compacta concepción monumental, y el de la expresión individual que califica la iconografía de las cabezas colosales. 
Ahora bien, es conveniente recordar que éstas constituyen un conjunto temático, pero muestran diferencias en cuanto a estilos locales y temporales (De la Fuente, 1975). Encuentro en la figurilla del Museo de Xalapa un mayor acercamiento a las esculturas de La Venta de la primera época (acaso entre 1000 y 800 a. de J. C.) cuando se tallaron las cabezas colosales de ese lugar; me apoyo en observaciones de la apariencia formal, el recogimiento compacto y geometrizante de sus elementos corporales y la expresión severa y gobernada de su rostro (figura 10). No encuentro mayor relación con las cabezas colosales de San Lorenzo, aun cuando la figurilla lleva en la banda del tocado un diseño parecido al de la Cabeza 1 del citado lugar; hay en las obras de San Lorenzo una animación, un sentido sensual y refinado de aproximación a la naturaleza de los cuales carece la figurilla del Museo de Xalapa. La distancia de forma y de contenido, se acrecienta en relación con las cabezas procedentes de Tres Zapotes y sus cercanías.

El parecido de la cabea de la figurilla del Museo de Xalapa con las cabezas colosales, plantea la posibilidad de que los individuos por éstas representados, se hayan figurado de cuerpo entero, a escala menor, o bien puede ser que se trate en este caso de un modelo singular.

En otras ocasiones he manifestado mi parecer respecto a lo que significan las cabezas colosales. Son, por una parte, retratos de personajes de primerísima importancia en la sociedad olmeca; acaso sacerdotes gobernantes o, tal vez, como se ha sugerido (Coe, 1972), individuos de real linaje de la dinastía del jaguar. Pero son, además, presencia concreta de profundas significaciones; en el orden perfectísimo de su estructura se repite el regulado concierto del cosmos.

No pretendo que la cabea de la figurilla del Museo de Xalapa se equipare en factura, en cualidades plásticas, en proporción armónica, en hondo significado, con las cabezas colosales. Es conveniente mantener la distancia debida entre una pieza interesante y original y obras inigualables en la historia del arte universal. Me limito a señalar lo que hay de semejanza entre ambas.

En resolución, por el carácter personal y esencialmente humano de la figurilla del Museo de Xalapa, pudiera pensarse que, al igual que en las colosales cabezas, se tratara de un retrato, o de un modelo para una obra mayor, pero con la intención de perpetuar la imagen de uno de los grandes señores olmecas. En todo caso, el elemento que porta en su casco simboliza también, como en las cabezas, su alta y determinada jerarquía. 
Figura de pequeñas dimensiones con aspecto de coloso, lleva consigo el sello inconfundible del arte olmeca; obra única de maestro, revela la importancia que a la individualidad humana se dio en tan sabia cultura.

\section{BIBLIOGRAFÍA}

Covarrubias, Miguel. Arte indigena de México y Centroamérica. Trad. Sol Argüedas UNAM, México, 1961

Coe, Michael D. "The Olmec Style and its Distribution". Handbook of Middle American Indians. The University of Texas Press. Texas, 1965, vol 3, pp. $739-775$.

- "Olmec Jaguars and Olmec Kings" The Cult of the Feline. A Conference in Pre-Columbian Iconography. Dumbarton Oaks Research Library and Collection. Washington. D. C. 1972, pp. 1-12.

De ia Fuente, Beatriz. Las cabezas colosales olmecas. Testimonios del Fondo. FCE México, 1975.

Pohorilenko, Anatole. "La Peqeña Escultura" El hombre y su expexiencia artístico-religiosa en El Arte Olmeca. Artes de México. México, 1972, núm. 154, año XIX.

Pre-Columbian Art. Robert Woods Bliss Collection. Text and Criti-Analyses by S. K. Lothrop, W. F. Foshag y Joy Mahler. Phaidon Press. London, 1957. 